REVISTA ANDALUZA DE ANTROPOLOGÍA.

NÚMERO 6: LOS MOVIMIENTOS SOCIALES Y LA CONSTESTACIÓN AL ORDEN GLOBAL.

MARZO DE 2014

ISSN 2174-6796

[pp. 11-30]

http://dx.doi.org/10.12795/RAA.2014.i06.01

Fecha de Recepción: 19-01-2014

Fecha de Aceptación: 26-02-2014

\title{
FEMINISMOS EN MOVIMIENTO EN EL ESTADO ESPAÑOL: ¿RE-AMPLIANDO EL ESPACIO DE LO POLÍTICO?
}

\author{
Lourdes Méndez Pérez \\ Universidad del País Vasco / Euskal Herriko Unibertsitatea
}

\section{Resumen.}

El artículo examina los feminismos en movimiento en el Estado español reteniendo que se inscriben en un contexto marcado por treinta años de Planes de Igualdad y por leyes recientemente promulgadas - de violencia de género, de matrimonio de personas del mismo sexo, de salud sexual y reproductiva, de identidad de género-, producto de las luchas feministas y las de los colectivos gays, lesbianos, transexuales y bisexuales. Esa aproximación permite bosquejar los desacuerdos entre feministas "institucionales", "nacionalistas", “otras", “queer", "postfeministas", "transfeministas", "FEMEN” (la lista no es exhaustiva); y sirve para pensar si es posible re- ampliar, desde posturas feministas a veces divergentes, el espacio de lo político.

\section{Palabras clave.}

Feminismos en movimiento, espacio de lo político, sujeto político, controversias feministas, micro-grupos, desacuerdos.

\begin{abstract}
.
The paper analyses Feminisms on the move in the Spanish State keeping in mind that they take place in a context affected by 30 years of Equality plans and recently passed Acts such as the Anti- Gender- based Violence Act, Same- sex Marriage Act, the Sexual and Reproductive Health Act, the Gender Identity Act. All these laws are product of the struggle carried out by Feminist, Gay, Lesbian and Transsexual groups. This approach
\end{abstract}


lets us outline the disagreements among different types of feminists such as Institutional Feminists, Queer, Nationalists, Others, Postfeminists, Transfeminists, FEMEN (the list is not exhaustive) and it is also useful to ponder whether it is possible to re- widen the political space from sometimes divergent feminist stances.

\section{Keywords.}

Feminisms on the move, political space, Institutional Feminism, micro- groups, disagreements.

"Pensar debemos", urgía Virginia Woolf a las mujeres en su combativo Tres Guineas. Transcurridos más de setenta años desde su publicación, más de cuarenta desde que en las postrimerías de la dictadura franquista se organizaran en la clandestinidad grupos feministas de diferentes ideologías, más de veinte desde la institucionalización del feminismo liberal, y más de diez desde que empiezan a fraguarse los primeros microgrupos feministas, urge pensar los feminismos hoy en movimiento en el Estado español. Y urge hacerlo porque vivimos un momento histórico en el que vemos peligrar derechos ya conquistados, y no cumplirse las expectativas de disminución de las desigualdades entre mujeres y varones prometidas por las políticas de igualdad. Y también porque vemos cómo en los últimos años han aumentado las controversias en un espacio político que también se produce discursivamente. Para pensar sobre los feminismos en movimiento primero desgajaré algunas cuestiones y, acto seguido, esbozaré el continuum de las luchas feministas y sus puntos de inflexión. Gracias a esas luchas se lograron derechos colectivos - educación, voto, aborto- fundamentales para quienes hemos sido socialmente asignadas a la categoría "mujer". En este artículo me voy a aproximar a los feminismos en movimiento en el Estado español reteniendo que se inscriben en un contexto marcado por treinta años de Planes de Igualdad y por leyes recientemente promulgadas - de violencia de género, de matrimonio de personas del mismo sexo, de salud sexual y reproductiva, de identidad de género- , producto de las luchas feministas y las de los colectivos gays, lesbianos, transexuales y bisexuales ${ }^{1}$. Esa aproximación me permitirá bosquejar las tensiones existentes entre feministas "institucionales", "nacionalistas", "otras", “queer", "postfeministas", "transfeministas", "FEMEN" (la lista no es exhaustiva).

\footnotetext{
1. Aprovechando su mayoría absoluta el PP pretende sustituir en 2014 la Ley de Salud Sexual y Reproductiva e Interrupción Voluntaria del Embarazo (2010) que reconocía el derecho al aborto, por la de Protección de los Derechos del Concebido y de la Mujer Embarazada en la que el aborto será delito. Por ahora no parece interesado por modificar leyes como la de Medidas de Protección contra la Violencia de Género (2004); la de Matrimonio de personas del mismo sexo (2005), y la de Identidad de Género (2007).
} 
También me servirá para pensar si es posible re- ampliar desde posturas feministas a veces divergentes el espacio de lo político en un periodo marcado por un neoliberalismo que ha provocado mutaciones a nivel mundial y uno de cuyos efectos fundamentales, pero no único, es el del incremento de las desigualdades socio- económicas. Incido sobre esto porque no debe descuidarse que como discurso ideológico el neoliberalismo forma parte de "la historia de las retóricas reaccionarias" (Audier, 2012: 616) y propugna, como estamos constatando, un conservadurismo moral beligerante con los derechos sexuales y reproductivos de las mujeres y con toda transformación social susceptible de alterar el carácter normativo de la diferencia sexual. Buenos ejemplos de ese conservadurismo moral son las virulentas reacciones en países como Francia ante la aprobación en 2013 de la Ley sobre el matrimonio entre personas del mismo sexo; o las crecientes diatribas sobre la familia, el matrimonio, las mujeres o la maternidad de insignes representantes de una Iglesia católica que, al amparo del Concordato ${ }^{2}$, mantiene una relación privilegiada con los sucesivos gobiernos de un Estado español constitucionalmente aconfesional. Hablar de feminismos en movimiento y no de movimiento feminista responde a una opción teórica atenta a que, a diferencia de otros movimientos sociales, desde finales de la década de los setenta el feminista tuvo que enfrentarse con la heterogeneidad del que había pensado como su sujeto político ${ }^{3}$ : la-s mujer-es. Como no podía ser de otra manera, reconocer la heterogeneidad (de clase, étnica, de práctica sexual, ideológica) de las mujeres afectó organizativa, política y teóricamente al único movimiento social compuesto, hasta fechas recientes, únicamente por personas de sexo femenino. A nivel organizativo el reconocimiento de dicha heterogeneidad se plasmó primero en sucesivas fragmentaciones del movimiento y, desde mediados de los noventa, en la proliferación de micro- grupos y en la emergencia de nuevas problemáticas y formas de activismo.

2. La política laica desarrollada durante la II República (1931- 1939), importante periodo para los logros feministas en España, llevó a la Santa Sede a considerar periclitado el Concordato. La dictadura franquista lo reactivó progresivamente adoptándose el definitivo en 1953. Tras la muerte de Franco se firmaron los todavía vigentes Concordatos de 1976 y 1979.

3. Iniciados en los setenta del siglo XX los debates intra- feministas sobre si las mujeres somos el sujeto político del feminismo han vertebrado los feminismos en movimiento y contribuido a su fragmentación. Hoy muy vivos, esos debates emergieron al hilo de teorizaciones feministas atentas a cómo afectaban a la construcción de una conciencia común las diferencias entre mujeres, las experiencias subjetivas sobre las identidades sexo-genérica, la clase social, la raza o la etnicidad, la heteronormatividad, o las categorías sexuales que estructuran el sistema patriarcal y el capitalista. La filosofía política feminista contribuye al debate con reflexiones sobre lo que entrañan para los sistemas democráticos los paradigmas políticos de la igualdad y de la diferencia, y sobre el cómo ampliar los límites de la democracia y de la ciudadanía de las mujeres sin que éstas, al igual que otros sujetos histórico colectivos minorizados, transiten por la teoría del sujeto del individualismo liberal. 
A nivel teórico condujo a intentar redefinir el sujeto del feminismo (Casado 1999) partiendo de algunas de las teorías sobre el género y las sexualidades elaboradas por autoras feministas lesbianas o por autores gays ajenos al feminismo. Y a nivel político, al igual que ya había sucedido en Estados Unidos o Francia, provocó enfrentamientos sobre - y cito algunos de los más virulentos- la postura a adoptar ante la prostitución: ¿abolirla o reglamentarla?; la pornografía: ¿censurarla o producir representaciones alternativas?; o el porte del velo islámico: ¿a favor o en contra? Dada la complejidad de un entramado en el que se entrelazan viejas y nuevas problemáticas, teorizaciones de muy diversa índole, variadas formas de organización y de activismo, y diferentes generaciones de feministas, este artículo propone un bosquejo del mismo.

\section{FEMINISMOS EN MOVIMIENTO, FEMINISTAS EN LUCHA}

Si existe una constante en la ya larga historia de los feminismos en movimiento es su aparente desintegración tras obtener ciertos derechos, y su sorpresiva reaparición bajo formas siempre renovadas para retomar combates emprendidos por antecesoras cuyas luchas a menudo las nuevas militantes desconocen ${ }^{4}$, o para iniciar otros nuevos. Ese desconocimiento no es la menor de las paradojas de unos feminismos que en el continente europeo se organizaron en movimiento casi a la par que lo hacía el movimiento obrero, lo que lleva a preguntarse "cómo la memoria de un movimiento tan significativo, el recuerdo de sus esfuerzos, de sus desafíos intelectuales y militantes, han podido borrarse tan fácilmente" (Offen, 2012: 31). Ese borrar la memoria de las luchas feministas contribuye a su habitual clasificación como "nuevo" movimiento social, lo que no ayuda ni a restituir su historicidad, ni a comprender sus periódicas reemergencias, ni a captar la heterogeneidad de un movimiento que desde finales de los sesenta del siglo XX no ha cesado de reinventarse. Quizás si pensamos ese movimiento en términos de "erupciones, de fisuras, de lava en fusión [...], como una forma amenazante e inasequible de descontento que no deja de atacar los puntos débiles de las capas de sedimentos acumulados que forman la coraza del patriarcado, el barniz institucional de las sociedades (logrando a veces abrirse un camino a través de ellas)" (Offen, 2012: 56), comprenderemos mejor sus apariciones, sus desapariciones y sus solapamientos. Además hay que insistir en que el feminismo "engloba a un tiempo un conjunto de ideas y un

4. Conscientes de esta problemática desde instancias institucionales como la Comision de Igualdade do Consello da Cultura Galega, conformada por feministas, al igual que desde grupos militantes como Bilgune Feminista (Euskadi), se trabaja en la recuperación de la memoria y documentación del Movimiento Feminista Organizado. En Galicia los primeros resultados se publicaron en 2013. En Euskadi la publicación aún pendiente reúne documentos producidos por grupos feministas de la Comunidad Autónoma Vasca y del País Vasco francés. 
movimiento de cambio social y político fundamentado sobre el rechazo de los privilegios masculinos y de la subordinación de las mujeres en una sociedad determinada" (Offen, 2012: 51). En los años setenta del pasado siglo ese doble rechazo obligó a los estados de Europa occidental, sorprendidos ante la erupción de un feminismo en movimiento integrado por ciudadanas con derecho a voto, "a crear estructuras que se encargasen de las cuestiones de la igualdad entre los sexos" (Dauphin, 2010:15) y, a nivel internacional, la onda expansiva de esa erupción feminista se dejó oír cuando las Naciones Unidas proclamaron 1975 Año Internacional de la Mujer.

En un Estado español que a finales de aquel año dejaba tras de sí cuarenta años de dictadura franquista, saldrán de la clandestinidad grupos feministas (Moreno, 1977) vinculados a partidos y sindicatos de izquierdas - comunistas y socialistas- que se habían mantenido activos en la lucha anti- franquista ${ }^{5}$. Dichos grupos de mujeres feministas que serán etiquetadas como "doble- militantes" (Folguera, 1988), superan sus divergencias ideológicas y crean plataformas que, en 1977, año en el que sin que participe ninguna mujer se inicia la redacción de una Constitución que sólo tendrá "padres", y año también de las primeras elecciones democráticas, proponen a los partidos un "proyecto común mínimo resultante de las tensiones entre los diferentes grupos feministas y los partidos políticos de los que algunas estaban cercanas" (Frottie, 2006: 81). Cuando en 1978 se aprueba la Constitución, el principio de igualdad entre los sexos y de nodiscriminación por razón de sexo o práctica sexual integra su articulado. Indudable logro institucional de un movimiento feminista cada vez más plural ideológicamente que, en las II Jornadas Feministas celebradas en 1979 en Granada ${ }^{6}$, además de oponer a feministas "de la igualdad" y "de la diferencia", empieza "a dividirse sobre la autonomía del feminismo como movimiento social y se plantea la cuestión de la participación de las mujeres en los partidos políticos así como en los aparatos del Estado" (Frottie, 2006: 82). Una división que también se manifiesta en la creación aquel mismo año del Partido Feminista de España (Falcón 2012) y que, como veremos, se repetirá en 2009 en la misma ciudad pero esta vez parcialmente suscitada por algunos efectos no deseados - al menos no por todas- de la institucionalización de ciertas corrientes políticas feministas sobre las luchas aún pendientes.

Aunque ya existía tanto en ámbitos internacionales como en otros países de la Unión

\footnotetext{
5. Aunque en menor medida también participaron activamente mujeres anarquistas y nacionalistas gallegas, vascas y catalanas.

6. Del 5 al 7 de diciembre de 2009.
} 
Europea ${ }^{7}$, la institucionalización de una determinada ideología política feminista, y los mecanismos que la acompañan empezó a fraguarse en el Estado español cuando, utilizando su mayoría absoluta y a instancias del grupo Mujeres y Socialismo, el Partido Socialista Obrero Español (PSOE) aprobó en 1983 la creación del Instituto de la Mujer. Ese organismo, del que también se dotarán algunas Comunidades Autónomas, recurrirá cada vez más a expertas académicas en género para diseñar planes de igualdad basados en políticas neoliberales internacionalmente consensuadas y respetuosas de los intereses de los estados, incluido el Vaticano. Desde los Institutos de la Mujer se impulsará el asociacionismo ${ }^{8}$ promoviéndose la onegeización de los grupos de mujeres y/o feministas argumentando que con eso pretenden que las mujeres participemos en la vida sociopolítica. Lo que esos organismos no dicen es que ese impulso les permite ejercer un control sobre los grupos de mujeres, feministas o no. Control en la medida en que, para subsistir y poder desarrollar sus proyectos, dichos grupos solicitan subvenciones convirtiéndose así en grupos institucionalizados que existen gracias a la financiación pública. Esa situación beneficia doblemente a los Institutos de la Mujer ya que, por una parte, auto- legitima su función y, por otra, anula toda posible crítica feminista ante sus propuestas ya que éstas serían producto de un amplio consenso recabado tras consultar a todas las asociaciones censadas (Méndez, 2008). A quien no beneficia la situación es a un movimiento feminista que se irá fragmentando en múltiples asociaciones que encontrarán cada vez mayores dificultades para diseñar idearios políticos comunes. Para transitar por algunos de los vericuetos de esa compleja realidad voy a recurrir a dos eslóganes feministas de los setenta- ochenta aún hoy presentes quizás porque ya no se interpretan como reivindicaciones, sino como auto- afirmaciones emitidas por sujetos autónomos: "mi cuerpo es mío" y "lo personal es político".

Reivindicando la propiedad de sus cuerpos las feministas occidentales abrieron la caja de Pandora. Y no por exigir a los estados democráticos que reconocieran derechos sexuales a sus ciudadanas ${ }^{9}$, o por pedir que se respetara su libertad sexual. La abrieron al iluminar lo que había sido social y políticamente escamoteado - la violencia machista en los espacios domésticos, el acoso sexual en el mundo laboral, los malos tratos físicos y

\footnotetext{
7. Las estrategias políticas en torno a la institucionalización del feminismo de la igualdad desarrolladas por los estados francés y español presentan interesantes paralelismos, en especial durante el mandato del socialista François Mitterrand, que coincidió parcialmente con el de los gobiernos de Felipe González.

8. En 2008 existían en el Estado español más de 3000 asociaciones de mujeres y/o feministas censadas.

9. En el Estado español una tímida ley de despenalización del aborto siempre que se dieran tres supuestos - violación, malformación del feto, peligro psicológico y/o físico para la madre- se aprobó en 1985 durante el gobierno con mayoría absoluta de un PSOE más atento a las hipotéticas reacciones adversas de las fuerzas de derechas y de la Iglesia católica, que a los derechos de las mujeres y a las fuertes movilizaciones feministas de aquellos años.
} 
psíquicos, la lesbofobia, la homofobia y la transfobia- , y al hacer emerger cuestiones que como las de la prostitución, la pornografía o el lesbianismo, fragmentaron el feminismo organizado ${ }^{10}$ de aquellos años y que, como se verá, oponen hoy a diferentes grupos de feministas en movimiento. Pero examinemos ahora el segundo de los eslóganes. Si algo caracterizó a las feministas de los setenta es que aún estando adscritas a diferentes corrientes políticas, aún estando en desacuerdo sobre cuáles eran las principales causas de la opresión de las mujeres y, en consecuencia, estando también en desacuerdo sobre las estrategias a desarrollar para conseguir transformar la situación de éstas; es que pensaron como políticos todos los ámbitos en los que las personas desarrollamos nuestras vidas, y todas las experiencias que vivimos. El eslogan "lo personal es político" atravesó las fronteras de los estados occidentales haciéndola suya feministas que no compartían una misma ideología política - igualitarias, diferencialistas, ecofeministas, radicales, liberales, materialistas, socialistas, marxistas, nacionalistas- , e insistiendo en que las luchas feministas atravesaban todas las luchas sociales. La idea de que los feminismos son transversales a toda lucha de emancipación fue aceptada por todos los partidos y movimientos sociales de las izquierdas por así decirlo "clásicas", como por un plural movimiento altermundialista ${ }^{11}$ constituido por diversos grupos organizados que rechazan la globalización neo- liberal y cualquier forma de desigualdad y discriminación. Ni en las organizaciones de las izquierdas "clásicas", ni en el movimiento altermundialista, encuentran las feministas pruebas fehacientes de que dicha asunción teórica se haya concretado en la práctica, lo que les conduce a reflexionar sobre cómo atacar desde los feminismos en movimiento a un patriarcado que, él sí, es tan transversal en los "viejos" como en los "nuevos" movimientos sociales (Lamoureux, 2004).

Desde sus inicios, y al igual que lo fueron los otros grandes movimientos sociales, el movimiento feminista fue transnacional, quizás por eso constatamos hoy que las reivindicaciones feministas se han internacionalizado, que se han creado redes transfronterizas institucionales o alternativas, que las propuestas políticas del feminismo liberal se han institucionalizado, y que en diversos países se han desarrollado activismos queer y transfeminismos en tensión, o en franca ruptura, con algunas claves políticas de los feminismos de los setenta- ochenta del siglo XX. Todos esos factores tan presentes en el Estado español como en otros (Bard 2012), son los que hay que tener en cuenta para

10. Desgajándose total o parcialmente del movimiento gay y/o del feminista, desde mediados de los ochenta empiezan a crearse los Colectivos de Feministas Lesbianas. Además de manifestarse ocupando el espacio público cada 28 de Junio, Día del Orgullo, editarán revistas como Nosotras, que nos queremos tanto (Madrid), El amor existe entre mujeres (Euskal Herria), o Tríbades (Barcelona).

11. Se considera que el movimiento altermundialista emerge en Seattle en noviembre de 1999 durante la manifestación contra la Asamblea General de la Organización Mundial del Comercio (OMC). 
comprender los feminismos actualmente en movimiento y ver si éstos re- amplían, o no, el espacio de lo político. Es decir, para ver si han logrado incorporar a dicho espacio, y de qué forma lo han hecho, lo que hasta ahora ha quedado fuera de él o ha sido minorizado, a saber, unas políticas feministas "otras, la desestabilización de las jerarquías, la lucha por la igualdad - sí, pero no en cualquier tipo de mundo- [...,] (unas políticas feministas) cuyo fin no es conquistar la norma dominante sino interrogar la posibilidad misma de la dominación" (Puig de la Bellacasa 2012: 52).

\section{UNA NECESARIA REORGANIZACIÓN: FEMINISMOS EN TRÁNSITO ENTRE NUEVAS REALIDADES Y VIEJAS PROBLEMÁTICAS}

Aunque rara vez se explicita y mucho menos se analiza en términos de relaciones de poder, hoy en día actúan en el espacio político, en el académico y en el vinculado a la producción de representaciones artísticas, tres generaciones de feministas que no comparten - aunque puedan aliarse coyunturalmente- los mismos postulados políticos y teóricos: las que empezaron las luchas bajo la dictadura franquista, las que iniciaron su andadura al filo del siglo XXI, y las que a principios de los ochenta se incorporaron a un movimiento que, como ya he señalado, ya se había dividido entre feministas "de la igualdad" y "de la diferencia". A esa primera fragmentación le siguió, como también he indicado, otra que se produjo pocos años después cuando las feministas lesbianas, hasta entonces integradas en el movimiento feminista, se desgajaron de él para crear sus propias organizaciones. Al hacerlo se visibilizaron como sujeto histórico colectivo doblemente oprimido - por su sexo y por su práctica sexual- y denunciaron, nutriéndose de los estudios que historizaban la sexualidad, los múltiples efectos de una heteronormatividad a la que las feministas heterosexuales habían prestado escasa o nula atención política. He esbozado este escenario por tres motivos. El primero, porque incide en la temprana fragmentación del movimiento feminista y da cuenta de la emergencia de nuevos sujetos (Trujillo 2009) cuyas demandas exigirán la renovación de la agenda política feminista. El segundo, para llamar la atención sobre el hecho de que una de las características de los feminismos en movimiento es la retroalimentación, en cada una de sus erupciones, entre las luchas que se emprenden, las reivindicaciones que se formulan y las teorizaciones que las arropan. Y el tercero, porque conviene recordar que cada nueva erupción la suscitan mujeres jóvenes que, aunque pueden desconocer las luchas feministas pasadas y las teorías que las acompañaron, han nacido en el marco de las nuevas realidades sociosexuales y políticas que aquellas hicieron posible. Esbozado el escenario, y expuestos los motivos que me han llevado a hacerlo, voy a seguir avanzando en el complejo entramado de los feminismos en movimiento.

$\mathrm{Al}$ igual que buena parte de las feministas militantes de principios de los ochenta, las que empezaron su andadura mediados los noventa también habían cursado estudios universitarios. Sin embargo a diferencia de sus antecesoras, y al menos en un primer 
momento, éstas no se aproximarán a las luchas feministas desde la praxis y la asunción identitaria del sujeto político "mujeres", sino desde teorías de género que se interrogaban sobre dicho sujeto y que ya se habían abierto un espacio en los estudios universitarios gracias a las luchas de las "feministas académicas". Buen ejemplo de dichas luchas fue la aprobación en 1988 del Instituto de Investigaciones Feministas de la Universidad Complutense de Madrid, cuyos orígenes se remontan a $1983^{12}$. Lo que me gustaría que se tuviera presente es que en un breve lapso temporal toda una generación se había beneficiado, y se había visto afectada en sus deseos de transformación política, por la progresiva pérdida de visibilidad de los grupos que componían los feminismos radicales, por la institucionalización del feminismo liberal, y por la presencia de conocimientos elaborados desde perspectivas feministas (Adán 2006) o de género en diversos estudios universitarios $^{13}$. Para entender por qué, mayoritariamente, quienes a mediados de los noventa se sienten interpeladas/os por estas cuestiones giran su mirada hacia las teorías de género acuñadas en Estados Unidos, y parecen fascinadas/os por debates que - como el de la pornografía o la prostitución- tuvieron lugar en aquel país a principios de los ochenta, hay que saber que se mueven en un contexto sustancialmente diferente del que acogió a la anterior generación. Un contexto en el que empezaban a cobrar entidad algunos micro- grupos de activistas- artivistas muy críticos con la institucionalización del feminismo liberal (Valiente 1996), muy insatisfechos con lo transmitido desde el feminismo académico, muy descontentos con los derroteros reformistas seguidos por los colectivos gays y lesbianos, y quizás ante todo deseosos de construir nuevas posiciones teóricas y políticas desde las que luchar. Incido sobre estos hechos porque son los fundamentos de tres fenómenos que se iniciaron en aquella década: el de la irrupción en el espacio político abierto por el feminismo de los ochenta de nuevos sujetos que demandan reconocimiento -transexuales, transgénero y travestis, el de la nueva realidad organizativa de unos feminismos en movimiento configurados por una constelación de micro- grupos, y el de un incipiente artivismo que culminará, mediada la primera

12. En 1983 profesoras y alumnas de doctorado de la Universidad Complutense de Madrid se reunieron en torno a la ya fallecida historiadora María Carmen García Nieto. En 1985 organizaron el Encuentro Internacional "Mujeres, ciencia y práctica política" en el que, entre otras, participó Celia Amorós, primera directora del Instituto de Investigaciones Feministas. Cuando ya existían en algunas universidades seminarios de estudios de la mujer - el primero de ellos se creó en la Universidad Autónoma y lo dirigió la socióloga María Ángeles Durán- que no siempre gozaban de un claro estatus dentro de la institución, la opción de las impulsoras del citado Instituto fue clara: luchar para que la Junta de Gobierno de la Complutense lo reconociera como Instituto, y apostar por "investigaciones feministas" y no por "estudios sobre la mujer".

13. Incluidos los Másteres en Igualdad y/o en género requeridos para profesionalizarse como "Técnicas/ os de Igualdad". 
década del 2000, en la estetización ${ }^{14}$ de la idea butleriana de "performatividad de género". Esta inédita tesitura es el escenario que acogerá y hará posible el surgimiento en el Estado español de los "nuevos feminismos" y los "transfeminismos", y la que ayuda a entender sus filiaciones teóricas y posiciones políticas. Retenerla permite detectar el impacto de las teorías posmodernas sobre las teorías queer y transfeministas y hace posible preguntarse si dos Manifiestos hechos públicos en el Estado español: "Un feminismo que también existe" (2006) y “ Manifiesto para la insurrección transfeminista” (2009), además de reorganizar a parte de las feministas, contienen propuestas susceptibles de re- ampliar el espacio de lo político o si, al contrario, y más allá de dejar patente la heterogeneidad ideológica de los feminismos en movimiento, "reflejan la ausencia de identificación con un universo de sentido compartido" (Bereni 2012 : 38). He seleccionado ambos manifiestos no porque no existan otros - desde sus inicios los feminismos en movimiento optaron por esa vía expresiva (Moreno Seco 2005) - sino porque delinean intersecciones entre quienes se consideran como parte del feminismo que no llegó al poder (Uría 2009) y pertenecen a la primera o a la segunda generación de feministas, y quienes se autodefinen como transfeministas y forman parte de la tercera. Para captarlas primero voy a transcribir parte del "Manifiesto para la insurrección...": Somos las bolleras, las putas, lxs trans, las inmigrantes, las negras, las heterodisidentes... somos la rabia de la revolución feminista [...] El sujeto político del feminismo "mujeres" se nos ha quedado pequeño, es excluyente por sí mismo, se deja fuera a las bolleras, a lxs trans, a las del velo, a las que ganan poco y no van a la uni, a las que gritan, a las sin papeles, a las marikas... Dinamitemos el binomio género y sexo como práctica política. [...] ¡Nuestros cuerpos son nuestros! [...] No necesitamos protección sobre las decisiones que tomamos en nuestros cuerpos, transmutamos de género [...] El feminismo será transfronterizo, transformador, transgénero, o no será, el feminismo será TransFeminista o no será... ${ }^{15}$. Según el Manifiesto y dada la cantidad de personas que el sujeto político "mujeres" excluye, éste sólo estaría integrado por heterosexuales de sexo/género femenino, blancas, universitarias, de clase media, no islámicas y con un salario confortable. Aceptando que eso sea así, y suponiendo que ninguna de las queer y transfeministas forjadoras y firmantes del texto compartan característica alguna

14. La relevancia de esa cuestión requeriría de otro artículo. Sólo apunto aquí que el fenómeno se ancla institucionalmente en el Museo de Arte Contemporáneo de Barcelona y se plasma académicamente en un Programa de Estudios Independientes auspiciado por la Universidad Autónoma de Barcelona. En él interviene habitualmente Beatriz Preciado, académica queer y figura de referencia para los microgrupos transfeministas. El fenómeno también concierne a seminarios, talleres o jornadas organizadas por centros culturales como Arteleku (Euskadi) o la Universidad Internacional de Andalucía (UNIA).

15. Firmado por colectivos y también a título individual por algunas investigadoras y académicas queer. "Manifiesto para la insurrección transfeminista" (2009) http://medeak.blogspot.com.es 
con el sujeto político del feminismo, podemos plantear algunas preguntas. ¿Ayuda la multiplicidad del sujeto transfeminista a ampliar el espacio de lo político? ¿Es útil para articular luchas políticas transformadoras de las condiciones de vida de, por ejemplo, una transexual femenina lesbiana negra inmigrante sin papeles prostituta y portadora de velo islámico en Andalucía? ¿Qué significa optar como práctica política por dinamitar el binomio sexo/género? La por ahora breve andadura de un transfeminismo deudor de la teoría queer y que ha estado más presente en los espacios artísticos que en los políticos, impide contestar a estas preguntas. Sin embargo sí podemos iluminar esa andadura, y parte de la de los "nuevos feminismos" (Gil 2011), a la luz de la línea del tiempo que figura al final de un libro sobre transfeminismo que sería "algo así como una antología de textos para acercarnos a lo que podrían ser las bases de un movimiento" (Solá 2013: 15). Un libro "a medio camino entre la teoría y la práctica, el arte y la política, la militancia o la academia que pretende reconstruir una parte de nuestro presente y de nuestro activismo a través, y desde el interior, de nuestra comunidad. [...] Se trata de un proyecto inacabado, parcial y situado" (id: 16). Atendiendo a estas indicaciones, consideraré como un esbozo inacabado de lo que resulta significativo para "la comunidad" "una línea del tiempo transfeminista" que cierra la antología y que se inicia en el año 1985. Seis son los ítems retenidos en ella: acontecimientos históricos, seminarios \& jornadas, colectivos, publicaciones, films \& documentales y exposiciones artísticas; y cuatro sus principales localizaciones: Madrid, Barcelona, Donostia y Sevilla. Si pasamos de puntillas sobre el hecho de que la aprobación en 1985 de la ley del aborto no aparece en ella - si lo hace la de 2010 - lo que se despliega en todos los ítems remite a cuerpos, géneros, sexualidades y deseos. A medida que se avanza en la línea se ve que el término "feminismo" aparece de forma cada vez más ocasional limitándose a los años en los que se celebran las Jornadas feministas estatales o que se producen acciones de okupación feministas. Que a partir del 2000 domina el término "género" y las teorías en torno a él ${ }^{16} \mathrm{y}$ las cuestiones trans (sexual, género). Que el "feminismo" no resurge más que como "feminismo pornopunk" (2008) o como "transfeminismo" (2010). Que se obvia el Manifiesto de las "feministas indignadas" que convergieron el 15M (VVCC 2012). Que exposiciones artísticas, films y documentales ocupan cada vez mayor espacio y retroalimentan los contenidos de jornadas y seminarios (o viceversa).

Lo que esta línea del tiempo ilumina es cómo ha ido tejiéndose una red que las feministas lesbianas de los ochenta empezaron a fraguar al inscribir en el espacio político del feminismo la discriminación sexual, las fuentes a las que quienes hoy integran dicha red recurren para elaborar sus discursos, y el desplazamiento de sus propuestas del espacio de la expresión política, al de la expresión artística. Lo preocupante no es tanto

16. De una selección de textos de Teresa de Lauretis a las obras de Judith Butler, pasando por Mónica Wittig, Donna Haraway, Virginie Despentes o Beatriz Preciado, entre algunas otras (y otros). 
el desplazamiento, necesario para producir representaciones alternativas sobre las sexualidades y darlas a conocer aunque sólo sea en los poco transitados espacios del arte contemporáneo, sino que indique que el artístico es el único espacio permeable a las propuesta formuladas. Quizás Beatriz Preciado, académica queer cuyas obras ocupan un importante lugar en la línea del tiempo que el libro propone, no fuera consciente de esa posibilidad al apostar por "un feminismo lúdico y reflexivo que escapa al ámbito universitario para encontrar en la producción audiovisual, literaria o performativa sus espacios de acción. [...] un nuevo feminismo posporno, punk y transcultural [...] (cuyo objetivo) no sería tanto liberar a las mujeres o conseguir su igualdad legal como desmantelar los dispositivos políticos que producen las diferencias de clase, de raza, de género y de sexualidad haciendo así del feminismo una plataforma artística y política de invención de un futuro común" ${ }^{17}$. Si algo ha sido siempre el feminismo es una plataforma política desde la que lograr un futuro común. Sin embargo, construirlo como plataforma artística y política requeriría no reducir las complejas teorizaciones y luchas de los feminismos en movimiento al logro de la igualdad y a un ámbito universitario al que, recordémoslo, ha accedido muy recientemente. Un ámbito al que, conviene también recordarlo, pertenece esta autora al igual que parte de quienes se piensan como transfeministas.

Como ha sucedido a lo largo de la historia de los feminismos en movimiento y a pesar de que sólo han transcurrido cuatro años desde que emergió, el transfeminismo ya es objeto de las primeras críticas internas que se centran en tres cuestiones: la de si está superado o no el feminismo; la del sujeto "mujeres", y la del "ombliguismo" (Ziga 2013). Itziar Ziga, cuyas obras también están muy presentes en la línea del tiempo, aborda la primera cuestión insistiendo en que si se habla sólo de la institucionalización del feminismo y se incide en que éste prioriza a las mujeres burguesas, blancas, heterosexuales, se estaría negando "a todas las feministas autónomas. Obreras, radicales, putas, gitanas, bolleras que operaban en dicho momento" (Ziga 2013: 83). Ante la segunda cuestión monta "en cólera (al escuchar) que no debemos seguir hablando de mujeres. Claro, a partir de ahora somos globos de helio suspendidos en el limbo social. No somos ni hombres ni mujeres. Ni blancas ni negras [...] ni putas ni heteros. [...] ni seropositivas ni cojas. Quienes andan siempre con esta monserga y parece molestarles más el binarismo que la opresión, que vayan a decirle a una mujer negra que en realidad no es ni mujer ni negra" (id: 84). Y, frente al "ombliguismo" que se palpa en el fenómeno de las jornadas afirma que "tiene que llegar la acción. [...] (el potencial del transfeminismo) es que nos aglutinamos desde el rechazo más radical e irrenunciable al capitalismo, a la democracia de partidos, al racismo, al control policial, al europeísmo, a las trampas de la modernidad, al desarrollismo, y no

17. Babelia del 13 de enero de 2007 Después del Feminismo, entrevista a Beatriz Preciado seguida de: Biblioteca mínima del feminismo posporno, queer y poscolonial. Las referencias bibliográficas que figuran en el apartado de publicaciones de Una línea del tiempo transfeminista. 
sólo al patriarcado (única lucha común de todos los feminismos) (id: 86). Aunque el potencial del transfeminismo sean esos múltiples rechazos, la pregunta que se impone es la de cómo llegar a la acción a través de él, pero Ziga no proporciona pistas sobre cómo hacerlo sino que enuncia esa necesidad.

El "Manifiesto para la insurrección transfeminista" tras recordar el eslogan del feminismo de los setenta ¡Nuestros cuerpos son nuestros! afirma que "no necesitamos protección sobre las decisiones que tomamos en nuestros cuerpos" idea ya presente pero expresada en otros términos en el Manifiesto "Un feminismo que también existe" hecho público en $2006^{18}$. Sensiblemente más largo que el transfeminista, escrito en un tono radicalmente diferente puesto que su público es otro - el de quienes integran el feminismo institucional-, sus firmantes se piensan como voces silenciadas por dicho feminismo con el que disienten en cuestiones clave. Significativo de este Manifiesto es que, a la par que considera positivos los avances logrados por el gobierno de J.L Zapatero en el terreno de la igualdad entre mujeres y hombres y su plasmación legislativa, saca a la luz viejas problemáticas también presentes en otros países (Badinter 2003). Entre ellas, la de que la excesiva tutela legal sobre la vida de las mujeres podría derivar en su construcción como víctimas lo que nos haría "un flaco favor pues no tiene en consideración nuestra capacidad para resistir, para hacernos un hueco, para dotarnos de poder, porque no ayuda tampoco a generar autoestima y empuje solidario entre las mujeres". La de que no puede asumirse la idea de violencia de género que sustenta la ley de su mismo nombre y que estaría basada en "la idea del impulso masculino de dominio' como único factor desencadenante [...] no existe, en nuestra opinión, una naturaleza masculina perversa o dominadora". La de que la apuesta por una "filosofía del castigo" presente en la citada ley sería propia de un "tipo de feminismo" que considera "el castigo como solución para poder resolver los problemas y conflictos sociales". Y la de que se considere la prostitución, al igual que lo hacía el feminismo puritano decimonónico "una actividad indigna y degradante [...] buena excusa para mantener las pésimas condiciones en las que las prostitutas ejercen el trabajo". Como punto final del Manifiesto, una declaración de intenciones: "el objetivo del feminismo debe ser el de acabar con las conductas no igualitarias, con las conductas opresivas y discriminatorias; debe ser el de conseguir la igualdad entre los seres humanos, no aniquilar a quienes discriminan u oprimen. Nosotras no deseamos configurar un feminismo revanchista y vengativo, deseamos simplemente relaciones de igualdad, respetuosas, saludables, felices". Es de esperar que al menos este último deseo lo compartan todas las feministas, e incluso las que no lo son, y sea cual sea su posición política. Sea como sea tras hacer

18. El País publicará el 18 de marzo de 2006 un artículo firmado por Empar Pineda, una de las impulsoras del Manifiesto hoy accesible en http://www.accionenredmadrid.org 
público el Manifiesto verá la luz una nueva red, la de "Otras voces feministas", compuesta por "mujeres vinculadas al feminismo desde los principios del movimiento y que no nos sentimos representadas en las posiciones feministas mayoritarias que se dan en los debates sobre la violencia machista y la prostitución" (Garaizabal 2012: 256). Desde un primer momento la nueva red organiza anualmente encuentros en los que abordan problemáticas ligadas al cuerpo, la prostitución, el trabajo sexual y la inmigración, la transexualidad y su despatologización, el aborto sin tutela y, en la celebrada en 2013, se plasma con total claridad el interés por la diversidad sexual y de género.

Dejemos por ahora a las "otras voces feministas" para proseguir el bosquejo de este complejo entramado recuperando la línea del tiempo transfeminista prestando atención a los colectivos que en ella figuran. Al hacerlo se ve que en ella no están presentes las "otras voces" pero sí dos colectivos que las alimentan parcialmente y ayudan a visibilizar intersecciones entre diversas generaciones de feministas. En la línea del tiempo figura Hetaira, colectivo compuesto por prostitutas y feministas defensor de los derechos de las prostitutas y co- fundado en 1995 por Cristina Garaizabal, una militante histórica firmante del Manifiesto "un feminismo que también existe"; y Medeak un mirco-grupoqueer constituido en 2000 y artífice del Manifiesto "para la insurrección transfeminista" redactado tras las jornadas feministas estatales que tuvieron lugar en 2009 en Granada. Si las celebradas en esa misma ciudad en 1979 acabaron en división política y organizativa entre feministas "de la igualdad" y de "la diferencia" y abordaron como eje reflexivo la lucha de clases y la opresión de las mujeres, las de 2009 hablaron de un feminismo "centrado en la disidencia activa y no en el victimismo; un feminismo consciente de la diversidad del ser mujer, que se hace eco de las injusticias y desigualdades (etnia, migrantes, violencia machista, opción sexual, diversidad corporal, las más jóvenes, las más mayores, las que trabajan en la industria del sexo"19. Durante tres días "más de 4000 feministas inundaron Granada [...] Mujeres de todos los colores, edades y orientaciones sexuales. Jóvenes con piercing y pañuelo palestino, mayores de pelo blanco, rapadas, chicazos, mujeres de larga melena con tacones altos y carmín, históricas del feminismo, transexuales, lesbianas, heterosexuales [...] Crisis, prostitución, violencia de género, aborto, sexualidad, falta de derechos de las empleadas de hogar, de las inmigrantes..." ${ }^{20} \mathrm{Y}$ tras la colorida descripción, y la enunciación de los temas tratados, la cronista afirma que "el debate sobre la prostitución está tan enconado [...] que la mesa redonda acabó con una bronca monumental entre las ponentes defensoras de reconocer derechos a las prostitutas, y unas asistentes abolicionistas que defendían que todas son víctimas"(20). Aunque el desacuerdo en torno a la prostitución (Valiente 2004) ya lo

19. Folleto de las jornadas "30 años después... ¿auún es necesario el feminismo?

20. El País de 13 de diciembre de 2009. 
habían expresado las firmantes de "un feminismo que también existe" y habían seguido haciéndolo las integrantes de "otras voces feministas", lo acaecido en Granada iluminará una insospechada convergencia de intereses entre los micro-grupos queer presentes, y una generación de feministas históricas claramente opuestas al feminismo institucional y partidarias de la reglamentación del trabajo sexual. Es esa parcial convergencia la que, a mi entender, explica por qué en noviembre de 2010, en el marco de la UNIA, se celebrara un "Seminario-Encuentro Movimiento en las bases: transfeminismos, feminismos queer, despatologización, discursos no binarios" en cuyas sesiones intervinieron Cristina Garaizabal, Beatriz Preciado, Itziar Ziga o Miriam Solá, por citar algunas de las que han sido mencionadas en estas páginas.

\section{ALGUNAS REFLEXIONES Y DOS IMÁGENES PARA UN EPÍLOGO}

El "Pensar debemos" de Virginia Wolff y la pregunta sobre si los feminismos hoy en movimiento en el Estado español están re-ampliando el espacio de lo político, me han servido de guías para redactar este artículo. Antes de proponer las imágenes que utilizaré como epílogo, quisiera incidir sobre algo básico: que los movimientos sociales han promovido cambios sociales y políticos sustanciales. Nadie negará que los feminismos en movimiento, en toda su diversidad y complejidad, con sus tensiones internas y estrategias divergentes, pero también con sus alianzas inquebrantables cuando se ataca a los derechos ya obtenidos por ese sujeto político "mujeres" que fue básico para echar a andar, una vez más, mediados los sesenta del siglo XX, es uno de los movimientos sociales que más fuerte y a más múltiples niveles ha calado. No en vano sus eslóganes clásicos "lo personal es político" y "nuestro cuerpo es nuestro" han atravesado décadas y siguen tan anclados en esa multiplicidad de micro-grupos feministas, queer, transfeministas, como en aquellos que apuestan por políticas sexuales más reformistas. Ambos siguen haciéndonos pensar. La demostrada capacidad de los feminismos en movimiento de interpelar a la sociedad en la que irrumpen, de suscitar controversias sobre temas tan delicados como el de las fluctuantes identidades sexo/genéricas, o el de la libertad sexual, o el del aborto, es una de sus mayores fuerzas. Al igual que fue una de las mayores fuerzas de nuestras antecesoras luchar por esos derechos ciudadanos que son la educación y el voto. Por eso habría que considerar a todos los feminismos en movimiento como organizaciones reflexivas (Laraña 1999) dada su capacidad para cuestionar públicamente una normatividad (de sexo, de género, de práctica sexual, de sumisión de la mujer al varón...) que hasta su irrupción no se consideraba social, sino "natural". Si la fuerza de los feminismos en movimiento es la de difundir ideas nuevas, su gran reto es el de lograr convencer ya que sólo así se conseguirá una transformación social significativa. Un gran reto al que hay que añadirle otro: el de cómo lograr que las feministas que actúan en un espacio político construido entretejiendo múltiples discursos -sobre la dominación, la exclusión, la igualdad, la violencia, el género, el patriarcado, la heteronormatividad, etc.,- $y$ que defienden 
diversos ideales de transformación social, "produzcan y pongan en circulación esquemas de percepción compartidos" (Bereni 2012: 40). Para producirlos hay que disponer de "un lenguaje político común vehiculado por instancias de socialización (libros, coloquios, manifestaciones, etc.): de retóricas, imágenes y eslóganes que materializan términos como "mujeres", “igualdad", “emancipación", “exclusión política de las mujeres"..." (id: 40). El problema reside en que para dar forma a dicho lenguaje hay que ser conscientes de que, más allá de sus divergencias, las feministas intervienen "en las luchas de sentido que se despliegan en torno a envites comunes (aborto, violencia, velo, prostitución, etc.). Participando en esas luchas aprenden tanto lo que les separa como lo que les une" (id: 40). En estas páginas hemos visto que las "otras feministas" se separan de las que, según ellas, han alcanzado el poder, y que los mirco-grupos queer y/o transfeministas también lo hacen. También hemos visto que la línea del tiempo transfeminista contiene los selectivos referentes -libros, coloquios, manifestaciones, exposiciones- que han permitido a los micro-grupos elaborar esquemas de percepción compartidos. Es ese entramado el que alimenta sus propuestas políticas y el que permite que nos preguntemos si han logrado ampliar el espacio de lo político para los feminismos o si, al contrario, yuxtaponer en él múltiples sujetos atravesados por muy diversas problemáticas no se estará convirtiendo en una trampa mortal para el propio proyecto teórico-político-artístico transfeminista. Si hay algo que no deberíamos olvidar es que para luchar políticamente hay que construir posiciones y lograr que éstas "permanezcan abiertas a su propia historicidad, [...] en los posicionamientos feministas, dicha construcción está atravesada por tensiones [...] y es la reapropiación de la herencia como un proceso de reclaiming, de (re)habilitación en especial de la subjetividad y del estatus "mujer", lo que permite entender por qué es compleja la posición mujer del feminismo" (Puig de la Bellacasa, 2012: 56). Posiciones, historicidad, herencia, referentes: todo eso es lo que debemos recuperar si queremos construir una lucha política en la que lo que nos una sea superior a lo que nos separa. La explosión de narrativas que todas se autoproclaman igualmente válidas es uno de los efectos práctica, teórica y políticamente paralizantes de la circulación de las teorías posmodernas, y de la erradicación de las teorías materialistas, por los espacios políticos de los feminismos en movimiento. Ha llegado el momento de pensar con un poco de sentido común la situación actual ahora que "sabemos que la crítica no altera las relaciones de poder y que de hecho éstas han sobrevivido e incluso se han fortalecido. [...] Quizás las teorías feministas más antiguas aún tienen algo que enseñarnos sobre lo que tenemos en común como mujeres, a pesar de las valiosas criticas del esencialismo que se han llevado a cabo desde entonces. [...] Podemos combinar las lecciones del feminismo posmoderno con la materialidad de las desigualdades encarnadas y estructurales para dar un paso más allá del actual impasse político y teórico" (Hemmings, 2011: 4).

Para concluir rescataré dos imágenes que condensan problemáticas no resueltas que nos conciernen a todas y que merecerían formar parte de un álbum que recogiera la pluralidad 
de los feminismos en movimiento en el Estado español. Ambas imágenes dieron pié a titulares y portadas y abrieron los informativos televisivos de cadenas públicas y privadas: la de la Ministra de Defensa del Gobierno del PSOE Carme Chacón pasando revista a las tropas en abril de 2008 en avanzado estado de gestación, y la de tres activistas del grupo feminista FEMEN-España mostrando en el Congreso de los Diputados, en octubre de 2013, sus sexuados torsos en los que se leía "el aborto es sagrado". La acción de este micro-grupo de reciente creación en el Estado español, fundado en Ucrania en 2008, fue una protesta política ante la inminente reforma de la Ley de Salud Sexual y Reproductiva e Interrupción Voluntaria del Embarazo. Pocos días antes de la acción de las FEMEN, pero sin conseguir despertar eco mediático, diversas manifestaciones feministas habían recorrido las calles de Sevilla, Bilbao, Barcelona o Madrid protestando ante la inminente reforma de la citada Ley y lanzado eslóganes que, como el de "si los obispos parieran el aborto sacramento", fueron acuñados por feministas de los ochenta en su lucha por el derecho a que las mujeres pudiéramos decidir si deseábamos, o no, interrumpir nuestros embarazos. Se compartan o no los idearios subyacentes tras ambas imágenes, tanto la de Carme Chacón como la de las FEMEN hubieran sido imposibles sin las luchas sufragistas por el derecho a la educación y al voto, y sin aquellas en pro de la libertad sexual y de la igualdad de oportunidades entre mujeres y varones de los setenta-ochenta del siglo XX. Último micro-grupo llegado al panorama de los feminismos en movimiento en el Estado español, las FEMEN se definen como feministas, así, a secas, y quizás por eso consideran que a ellas se les debe que el término, y sobre todo la lucha, vuelva a estar en la palestra. Las FEMEN dicen luchar, desde lo que denominan el "sextremismo", contra la desigualdad entre los salarios de hombres y mujeres, contra la violencia doméstica, la sumisión de las mujeres, la trata de mujeres. Mujeres, mujeres, mujeres. Al parecer vuelve el viejo sujeto político del feminismo de los setenta y lo hace desde el protagonismo otorgado por los medios de comunicación al desnudo torso sexuado -que se corresponde con los estereotipos de belleza femenina- que muestran las FEMEN en unas irrupciones políticas que siguen las pautas de acción de los comandos. Si uno de los objetivos de cualquier movimiento social es atraer el interés mediático cuando realizan una acción, y toda militante feminista sabe lo difícil que eso resulta, las FEMEN lo logran sin dificultad utilizando como cebo unos pechos desnudos que, recordémoslo porque quizás ahí resida el peligro de su posible desactivación política, siguen percibiéndose socialmente como emblemas de feminidad. Al fin y al cabo uno de los referentes míticos de los que dispone el pensamiento occidental, el de las amazonas que se habrían rebelado contra el poder de los varones, para llevar a cabo con mayor destreza sus acciones guerreras, se habían amputado voluntariamente un pecho lo que, simbólicamente al menos, las alejaba del ser mujer estética y sexualmente normativo. Sea como sea, cierto es que tampoco les resultó difícil atraer esa atención a las encorsetadas sufragistas cuando protestaban en las calles y se enfrentaban a la policía. Del corsé a los pechos desnudos, de las sufragistas a las FEMEN, 
de las "otras feministas" a las institucionales, de las "queer" a las "transfeministas", es ya larga la cadena de generaciones de feministas en movimiento. No la interrumpamos. 


\section{REFERENCIAS BIBLIOGRÁFICAS}

Adán, Carme (2006) Feminismo y conocimiento. De la experiencia de las mujeres al cíborg. A Coruña:Spiralia.

Audier, Serge (2012) Néo- libéralisme(s). Une archéologie intellectuelle. Grasset: Paris.

Badinter, Elisabeth (2003) Fausse route. Paris: Odile Jacob.

Bard, Christine (2012) "Écrire l'histoire des féministes: bilan et perspectives". En Christine Bard (Dir.) Les féministes de la deuxième vague. Rennes: Presses Universitaires de Rennes, pp. 13-26.

Bereni, Laure (2012) "Penser la transversalité des mobilisations féministes: l'espace de la cause des femmes". En Christine Bard (dir) Les féministes de la deuxième vague. Rennes: Presses Universitaires de Rennes, pp. 27-41.

Casado Aparicio, Elena (1999) “A vueltas con el sujeto del feminismo". Política y Sociedad (30): $73-91$.

Dauphin, Sandrine (2010) L'État et les droits des femmes. Des institutions au service de l'égalité? Rennes: Presses Universitaires de Rennes.

Falcón, Lidia (2012) La pasión feminista de mi vida. Barcelona: Ediciones de Intervención Cultural/El Viejo Topo.

Folguera, Pilar (1988) "De la transición política a la democracia: la evolución del feminismo en España durante el periodo 1975- 1988”. En VV.AA El feminismo en España: dos siglos de historia. Madrid:Pablo Iglesias, pp.111- 131.

Frottie, Brigitte (2006) "L'égalité des sexes en Espagne comme enjeu politique dans le processus de democratisation", Politique Européenne (20), pp. 75- 98.

Garaizabal, Cristina (2012) "Apuntes desde un feminismo que no llegó al poder", Desacuerdos. Sobre arte, políticas y esfera pública en el Estado español (7), pp. 246- 263.

Gil, Silvia L (2011) Nuevos feminismos. Sentidos comunes de la dispersión. Una historia de trayectorias y rupturas en el estado español. Madrid:Traficantes de Sueños.

Hemmings, Clare (2011) Why Stories Matter. The Political Grammar of Feminist Theory. London: Duke University Press.

Lamoureux, Diane (2004) “Le féminisme et l'altermondialisation". Recherches Féministes 17(2), pp. 171- 194.

Laraña, Enrique (1999) La construcción de los movimientos sociales. Madrid: Alianza Editorial.

Méndez, Lourdes (2008) "Entre la calle y las instituciones: nuevos desafíos para un feminismo globalizado". En La igualdad no es una utopía. Nuevas fronteras: avances y desafíos, Madrid: Ed. Thomson/Aranzadi, pp. 204- 211.

Moreno, Amparo (1977) Mujeres en lucha. El movimiento feminista en España. Barcelona: Anagrama. 
Moreno Seco, Mónica (ed) (2005) Manifiestos feministas. Antología de textos del movimiento feminista español (1965-1985). Alicante: Centro d'Estudis sobre la Dona, Universidad de Alicante.

Offen, Karen (2012) Les féminismes en Europe. 1700-1950. Rennes: Presses Universitaires de Rennes.

Puig della Bellacasa, María (2012) Politiques féministes et construction des savoirs. "Penser nous devons"'. Paris: L'Harmattan.

Solá, Miriam (2013) “Introducción". En Miriam Solá y Elena Urko (comps) Transfeminismos. Epistemes, fricciones y flujos. Tafalla: Txalaparta, pp. 15- 27.

Uría, Paloma (2009) El feminismo que no llegó al poder. Trayectoria de un feminismo crítico. Madrid: Talasa.

Trujillo, Gracia (2009) "Del sujeto político la Mujer a la agencia de las (otras) mujeres: el impacto de la crítica queer en el feminismo del Estado español". Política y Sociedad (46) 1- 2: 161-172.

Valiente, Celia (1996) "El feminismo institucional en España: el instituto de la Mujer, 1983-1994)”. Revista Internacional de Sociología (13): 163- 204.

Valiente, Celia (2004) "La política de la prostitución y el papel del movimiento de mujeres y los organismos de igualdad en España”, Revista de Investigaciones Sociológicas (105): $103-132$.

VVCC (2012) R-evolucionando. Feminismos en el 15M. Barcelona: Icaria/ASACO.

Ziga, Itziar (2013) “¿El corto verano del transfeminismo?” En Miriam Solá y Elena Urko (comps) Transfeminismos. Epistemes, fricciones y flujos. Tafalla: Txalaparta, pp. 81- 87. 